ENFOQUES JURIDICOS

REVISTA MULTIDISCIPLINAR DEL CEDEGS

ISSN 26832070

Número 04

julio-diciembre 2021
Artículo: "Testamento y herencia digital"

Armando Adriano Fabre

Modesta Lorena Hernández Sánchez

DOI: https://doi.org/10.25009/ej.v0i04.2574

\title{
Testamento y herencia digital
}

Recibido 07 mayo 2021-Aceptado 09 julio 2021

\author{
Armando Adriano Fabre* \\ Universidad Veracruzana. Xalapa-Veracruz, México \\ aadriano@uv.mx \\ Modesta Lorena Hernández Sánchez** \\ Universidad Veracruzana. Xalapa-Veracruz, México \\ modhernandez@uv.mx
}

RESUMEN: De acuerdo con los Códigos Civiles -federal y estatales- la regulación del testamento en México se ciñe sobre diversos supuestos en los que de forma oral o escrita $y$ desde diferentes escenarios, el testador puede establecer las condiciones que estime pertinentes para que se disponga de sus bienes y derechos, así como para que se cumplan determinados deberes después de su muerte. Partiendo de esa lógica, la información procedente de cuentas electrónicas de facebook, twitter, instagram, redes de mensajería, blogs, entre otros,
ABSTRACT: According to the Civil Codes federal and state- the regulation of the will in Mexico is limited to various assumptions in which orally or in writing and from different scenarios, the testator can establish the conditions that he deems pertinent so that his assets and rights, as well as for certain duties to be fulfilled after his death. Based on this logic, the information from electronic accounts of Facebook, Twitter, Instagram, messaging networks, blogs, among others, also make up the citizens' assets, because their

\footnotetext{
* Licenciado en Derecho por la Universidad Veracruzana campus Xalapa; Maestro en Derecho Constitucional y Amparo por la Universidad Veracruzana campus Xalapa; Doctor en Derecho por la Universidad de las Naciones campus Veracruz; Docente de la Universidad Veracruzana campus Veracruz; Vocal de la Cátedra de Excelencia de la Universidad Veracruzana "Mahatma Gandhi".

** Licenciada en Derecho por la Universidad Veracruzana campus Veracruz; Maestra en Derecho Penal y Juicio Oral por la Universidad de las Naciones campus Veracruz; Abogada postulante; Docente de la Universidad Veracruzana campus Veracruz; Vocal de la Cátedra de Excelencia de la Universidad Veracruzana "Mahatma Gandhi".
}

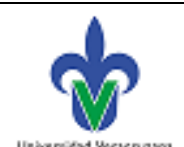


ENFOQUES JURIDICOS

REVISTA MULTIDISCIPLINAR DEL CEDEGS

ISSN 26832070

Número 04

julio-diciembre 2021
Artículo: "Testamento y herencia digital"

Armando Adriano Fabre

Modesta Lorena Hernández Sánchez

DOI: https://doi.org/10.25009/ej.v0i04.2574 también integran los bienes del ciudadano, en razón a que su presencia en la red está conformada con sus datos personales. Lo anterior, pone de manifiesto la necesidad de que la normativa en materia de sucesiones debe transitar hacia un nuevo paradigma que reconozca la regulación de los derechos que deriven del uso de las tecnologías de la información y comunicación como parte de nuestras actividades laborales, académicas, profesionales o recreativas. Tal es el caso de Francia y España, que han demostrado estar a la vanguardia al contemplar en sus legislaciones civiles la regulación del testamento digital, a fin de garantizar la gestión adecuada de las cuentas online de cualquier modalidad, después de la muerte de su titular.

Palabras clave: Testamento, identidad digital, sucesiones, pandemia, tecnologías de la información, notario, testador. presence on the network is made up of their personal data. The foregoing highlights the need for the inheritance regulations to move towards a new paradigm that recognizes the regulation of the rights that derive from the use of information and communication technologies as part of our work, academic activities, professional or recreational. Such is the case of France and Spain, which have proven to be at the forefront by contemplating in their civil laws, the regulation of the digital will.

Keywords: Will, digital identity, successions, pandemic, information technology, notary, testator.

SUMARIO: Introducción. 1. Generalidades sobre el testamento y sus modalidades. 2. El testamento emergente. 3. Las sucesiones en el ámbito virtual. 4. Regulación del testamento digital. Conclusiones. Fuentes de consulta.

\section{Introducción}

El dinamismo que caracteriza al derecho se traduce en la necesidad de adecuarlo a las situaciones y condiciones actuales que enfrenta la sociedad. Bajo esa tesitura, cada evento o avance tecnológico que ha surgido en el devenir del tiempo ha hecho evidente la obligación de tener esquemas vanguardistas en el ámbito educativo, económico, sanitario, político, laboral, y desde luego, jurídico.

La interacción del ser humano con el mundo cibernético ha dado lugar al surgimiento de derechos digitales que incluyen el uso de las plataformas que utilizamos de manera asidua, como por ejemplo: facebook, twitter, instagram, redes de mensajería, blogs, entre otras; las cuales representan un amplio espacio de libertad, responsabilidad y de las que nadie se ocupa cuando su usuario fallece.

Ante los retos que se vislumbran a consecuencia del uso de las plataformas virtuales, afirmamos que la legislación mexicana en materia de sucesiones -federal o estatal- se está

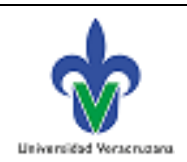

pp. $120-136$ 
ENFOQUES JURIDICOS

REVISTA MULTIDISCIPLINAR DEL CEDEGS

ISSN 26832070

Número 04

julio-diciembre 2021
Artículo: "Testamento y herencia digital"

Armando Adriano Fabre

Modesta Lorena Hernández Sánchez

DOI: https://doi.org/10.25009/ej.v0i04.2574

convirtiendo en obsoleta, dado a que hasta la fecha en la que se escribe la presente colaboración, no existe rubro alguno que regule los derechos procedentes del uso de las tecnologías de la información y comunicación, pese a que cada día el ser humano interactúa con mayor frecuencia en el mundo digital, como resultado del reconocimiento del acceso al internet como derecho humano.

En esa línea de ideas, esta colaboración tiene como objetivo especificar cuáles son los términos jurídicos que actualmente regulan las disposiciones testamentarias en México, con el propósito de identificar las carencias que presenta nuestra normativa en el tema, en comparación con la de países europeos como Francia y España, que jurídicamente tratan la identidad digital como patrimonio básico del de cujus. Se utilizan los métodos deductivo y comparativo, en razón a que la exposición del contenido se realiza de lo general a lo particular, contrastando la normativa mexicana contra la normativa europea en materia de testamentos escritos y digitales. Puntualizamos que los resultados obtenidos permiten afirmar que en México no se está protegiendo a plenitud la voluntad de los ciudadanos que otorgan un testamento.

Para finalizar, la presente colaboración consta de cuatro apartados: en el primero, abordamos el marco teórico y jurídico de la institución de la sucesión y el testamento en México; en el segundo, ahondamos sobre las formalidades para otorgar un testamento durante la pandemia SARS CoV-2; en el tercero, presentamos lo relativo a la regulación de la identidad digital como un rubro esencial del patrimonio personal, y en el cuarto, hablamos sobre el destino de los bienes digitales y su posterior legado.

\section{Generalidades sobre el testamento y sus modalidades}

La institución de la sucesión es una de las más lentamente elaboradas en la historia del derecho, dado a que en las primeras sociedades no existía una verdadera sucesión testamentaria y se desconocía el concepto de propiedad individual. Sin embargo, con la llegada del derecho romano en el año 753 a.C. comenzó a tomar forma la libertad de testar, de modo que las disposiciones hereditarias en un primer momento fueron primitivas, pero conforme se fueron ampliando las libertades, el derecho de testar y heredar bienes fue evolucionando a lo que hoy en día conocemos.

Ahora bien, el concepto del testamento ha sido definido por un sin número de autores y leyes. Todos los profesionales del derecho hemos leído distintas acepciones del término, sin embargo, existen definiciones que han sido consideradas como las más notables, mismas que exponemos a continuación:

Mucius Scaevola refiere que el testamento:

Es un acto espontáneo, personal, solemne y revocable, por virtud del cual una persona, según su arbitrio y los preceptos de la ley, dispone, para después de su muerte, tanto de su fortuna, como de todo aquello que, en la espera social en que vive, puede y debe ordenar en pro de sus creencias y de las personas que a él estén unidas por cualquier lazo de intereses (Barea, 1998, pág. 16).

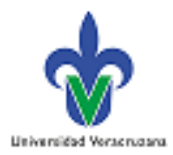

pp. $120-136$

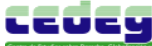


ENFOQUES JURIDICOS

REVISTA MULTIDISCIPLINAR DEL CEDEGS

ISSN 26832070

Número 04

julio-diciembre 2021
Artículo: "Testamento y herencia digital"

Armando Adriano Fabre

Modesta Lorena Hernández Sánchez

DOI: https://doi.org/10.25009/ej.v0i04.2574

Por otro lado, Bonnecase lo define como:

Un acto jurídico solemne, cuyo propósito es dar a conocer por parte de su autor, su voluntad para la época que se seguirá a su fallecimiento, tanto desde el punto de vista pecuniario como extra pecuniario, es esencialmente revocable, en él el testador a nada obliga. No es necesario que englobe todos los bienes del difunto y surte plenos efectos únicamente en caso de muerte (Bonnecase, 1993: 22).

En el mismo orden de ideas, sobresalen las definiciones de autores como Ruggiero, De Pina Vara, De Buen y Lozano, Rojina Villegas y Rodolfo Sohm, las cuales versan sobre la solemnidad con la que se manifiesta la voluntad del testador y los efectos jurídicos que produce después de su muerte.

A continuación, exponemos algunas generalidades que se deben tener en cuenta para estar en condiciones de otorgar un testamento y que, a su vez, representan la ejecución del principio de inmediatez del notario, dado a que es responsabilidad de este último, dar fe de que a su juicio los comparecientes tienen la capacidad legal para realizar el acto requerido, libertad del consentimiento, así como el conocimiento de la naturaleza y alcance del acto notarial (Ríos Hellig, 2012, pág. 79).

Con relación a la capacidad para testar, el artículo 1305 del Código Civil Federal, establece que pueden realizar un testamento todos aquellos a quienes la ley no prohíbe expresamente el ejercicio de ese derecho; por otro lado, el artículo 1306 señala que están incapacitados para testar:

I. Los menores que no han cumplido dieciséis años, ya sean hombres o mujeres;

II. Los que habitual o accidentalmente no disfrutan de su cabal juicio.

Respecto a los elementos que deben ser tomados en cuenta en cualquier sucesión testamentaria, se enumeran los siguientes: 1) el derecho del testador a disponer sobre la trasmisión de sus bienes para después de su muerte -mientras se encuentra con vida-; 2) el deber del testador de dar cumplimiento a las obligaciones con respecto a su cónyuge, hijos y otros familiares con quien los tenga por disposición de la ley y; 3) dar cumplimiento a cualquier otra obligación frente a terceros o que tenga arreglo a la ley (Pérez Contreras, 2010).

Según lo ordenado en el multicitado Código Civil Federal, podemos advertir como reglas de interpretación, las contenidas en los siguientes numerales:

Artículo 1300: "La disposición hecha en términos vagos a favor de los parientes del testador se entenderá que se refiere a los parientes más próximos, según el orden de la sucesión legítima".

Artículo 1302: "Toda disposición testamentaria deberá entenderse en el sentido literal de las palabras, a no ser que aparezca con notoria claridad que fue otra la voluntad del testador".

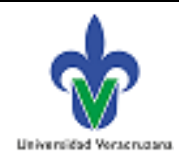

pp. $120-136$ 
ENFOQUES JURIDICOS

REVISTA MULTIDISCIPLINAR DEL CEDEGS

ISSN 26832070

Número 04

julio-diciembre 2021
Artículo: "Testamento y herencia digital"

Armando Adriano Fabre

Modesta Lorena Hernández Sánchez

DOI: https://doi.org/10.25009/ej.v0i04.2574

En caso de duda sobre la inteligencia o la interpretación de una disposición testamentaria, se observará lo que parezca más acorde a la intención del testador, según lo estipulado en el testamento y alguna prueba auxiliar que presenten los interesados.

Dicho lo anterior, también es conveniente mencionar que de acuerdo con el artículo 1344 y subsecuentes de dicho código, el testador es libre para establecer determinadas condiciones al disponer de sus bienes, bajo la premisa de que, si el heredero o legatario no cumple con alguna de las medidas impuestas, esto no impedirá que reciba lo que le corresponda, siempre que haya empleado todos los medios necesarios para cumplir con éstas. Ahora que, si se establecieran condiciones imposibles -por ejemplo: concertar una entrevista con Benito Juárez, entregarle una carta a Miguel Hidalgo, explorar los restos del Titanic, entre otras- se tendrán por no puestas; en el mismo sentido, se prohíbe obligar a una persona a poner disposiciones en su testamento a favor de otra persona, tampoco se pueden imponer obligaciones de no dar o no hacer, por ejemplo: prohibir la impugnación del testamento.

Ahora bien, es preciso señalar que a partir del artículo 1499 del Código Civil Federal, se advierte una clasificación entre los testamentos ordinarios y especiales; en ese contexto, el artículo 1500 menciona que son ordinarios aquellos que se otorgan en tiempos normales de vida, tales como: el testamento público abierto, público cerrado, público simplificado, y ológrafo; por otro lado, el artículo 1501 estipula que el testamento especial puede ser privado, militar, marítimo y hecho en un país extranjero.

Testamento público abierto: Bajo el criterio del jurista Asprón Pelayo, este documento Es el único que permite hacer un testamento con toda la asesoría que se requiera, además es perfecto desde el momento de su otorgamiento, en virtud no requerir ser declarado formal testamento, lo cual la ley lo consideró innecesario debido a que está redactado por un perito en derecho investido de fe pública: el notario, y, además, la voluntad del testador es conocida, no secreta (Asprón Pelayo, 2008, pág. 125).

Este tipo de testamento se encuentra regulado a partir del artículo 1511 al 1520 del mencionado código, que a grandes rasgos, especifica que se debe otorgar ante notario; el testador debe expresar de modo claro y terminante su voluntad a dicho fedatario público, quien a su vez, redactará por escrito las cláusulas del testamento, sujetándose estrictamente a la voluntad del testador y las leerá en voz alta para que manifieste si está de acuerdo, si así fuere, el notario, testador y testigos firmarán la escritura correspondiente.

En lo que atañe al Código Civil Veracruzano, del artículo 1444 al 1451 se estipulan las reglas sobre las que se rigen este tipo de testamentos en nuestro estado, puntualizando que no difieren de las formalidades que señala el Código Civil Federal.

Testamento público cerrado: El autor Burgi lo catalogó como un documento secreto que se otorgaba ante notario, porque solo se hacía entrega del pliego que lo contenía y el

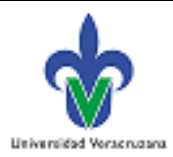

pp. $120-136$

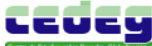


ENFOQUES JURIDICOS

REVISTA MULTIDISCIPLINAR DEL CEDEGS

ISSN 26832070

Número 04

julio-diciembre 2021
Artículo: "Testamento y herencia digital”

Armando Adriano Fabre

Modesta Lorena Hernández Sánchez

DOI: https://doi.org/10.25009/ej.v0i04.2574

notario no sabía si efectivamente tenía el testamento que el otorgante estaba señalando (Burgi, 2006, pág. 51).

Se encuentra regulado a partir del artículo 1521 al 1549 del Código Civil Federal, en los que se advierten diversas formalidades para que surta efectos su validez, desde cómo deben estar rubricadas las hojas en las que sea redactado, la ratificación y firma del testador, la necesidad de que el mismo se encuentre en un sobre cerrado y sellado, y que, de no hacerlo de esta manera, requerirá de la presencia de testigos. Por su parte, nuestro Código Civil Veracruzano -en seguimiento a la regulación del testamento en el Código Federal-contempla del artículo 1454 al 1482 la metodología jurídica que se debe utilizar para este tipo de acto jurídico.

Testamento público simplificado: Es uno de los más criticados por los autores del derecho civil al considerarlo un cuasi testamento, ya que no cumple con los principios que rigen a los testamentos, sin embargo, autores como Jorge Mario Magallón Ibarra afirma que es un avance que se le permita al adquirente de un inmueble destinado para vivienda, aprovechar la oportunidad de escriturarlo, y a su vez, otorgar su testamento respecto de dicho inmueble en el mismo acto jurídico en el que se consigna su adquisición y/o regularización (Magallón Ibarra, 1997, pág. 208). Se encuentra regulado en el artículo 1529 Bis del Código Civil Federal.

De igual modo, conviene puntualizar que conforme al criterio sostenido por el Cuarto Tribunal Colegiado en Materia Civil del Primer Circuito en la Tesis Aislada número 2017474, los herederos instituidos en un testamento simplificado están en la completa libertad de acudir a la jurisdicción del Estado o ante la función notarial para tramitar el juicio testamentario, en atención al derecho de acceso a la jurisdicción, ya sea mediante la tutela judicial o por los mecanismos alternativos de solución de controversias (Testamento público simplificado. El juicio sucesorio se puede tramitar judicialmente o ante notario, a elección de los herederos, 2018).

Testamento ológrafo: Es una de las formas más antiguas del testamento en la que el testador lo redacta y firma con la fecha de su otorgamiento, este debe estar cerrado y sellado, asimismo, debe estar impresa su huella digital. Una de sus características peculiares es que el sobre que lo contenga debe tener la siguiente leyenda: Dentro de este sobre se contiene mi testamento, además se debe poner el lugar y fecha en que se realiza el depósito; lo firma el otorgante, el encargado del Registro Público y los testigos. En el sobre que contiene el duplicado deberá plasmarse lo siguiente: Recibí el pliego cerrado que el señor afirma contiene original de su testamento ológrafo del cual existe dentro de este sobre un duplicado; cabe destacar que, para realizar este testamento el testador no es auxiliado por ningún notario. Las formalidades y requisitos para declarar su validez se advierten en los artículos 1550 al 1564 del Código Civil Federal, en la misma línea de ideas, nuestro Código Civil Veracruzano contempla su regulación a partir del artículo 1483 al 1497.

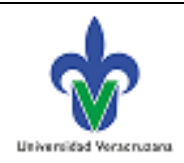

pp. $120-136$

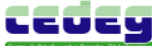


ENFOQUES JURIDICOS

REVISTA MULTIDISCIPLINAR DEL CEDEGS

ISSN 26832070

Número 04

julio-diciembre 2021
Artículo: "Testamento y herencia digital”

Armando Adriano Fabre

Modesta Lorena Hernández Sánchez

DOI: https://doi.org/10.25009/ej.v0i04.2574

Conviene señalar que este tipo de testamentos son susceptibles de interpretación, como lo señala el criterio sostenido por el Tercer Tribunal Colegiado en Materia Civil del Primer Circuito en la Tesis Aislada número 164661, dado a que en la mayoría de los casos el suscriptor no cuenta con asesoría legal al momento de formularlo y lo hace a su leal y saber entender (Testamentos ológrafos. Son susceptibles de interpretación, 2010).

Testamento privado: El artículo 1565 del Código Civil Federal dispone cuáles son los supuestos extraordinarios en los que se podrá otorgar este tipo de testamento, siendo los siguientes:

a) Cuando el testador se enferma repentina y gravemente, por lo que no le da tiempo de presentarse con el notario para hacer el testamento;

b) Cuando no haya notario en la población o juez que actúe para recibir y que deposite el testamento;

c) Cuando habiendo notario o juez, sea muy difícil que éstos concurran al otorgamiento del testamento;

d) Cuando los militares o asimilados entren en campaña o se encuentren prisioneros de guerra.

Para estar en condiciones de efectuarlo, es indispensable que el testador se encuentre completamente imposibilitado para realizar un testamento ológrafo. En la misma tesitura, el Código Civil Veracruzano contempla las mismas directrices en su regulación, a partir del artículo 1498 al 1511.

Testamento militar: Procede cuando el militar o asimilado del ejército entra en acción de guerra o se encuentra herido en el campo de batalla, por lo que, bajo esas circunstancias, es suficiente con que manifieste su última voluntad ante dos testigos o que le entregue a los mismos el pliego cerrado con su última disposición, firmado de su puño y letra. Se encuentra regulado a partir del artículo 1579 al 1582 del Código Civil Federal; de igual forma, a partir del artículo 1512 al 1515 del Código Civil Veracruzano se advierten las disposiciones relativas a éste.

Testamento marítimo: Las formalidades que reviste son muy similares al testamento militar, dado a que puede ser otorgado por personas que se encuentren en alta mar, a bordo de navíos de la Marina Nacional, sea de guerra o mercante. El testamento será escrito en presencia de dos testigos, así como del capitán del navío y será leído, datado y firmado como se establece para el testamento público abierto, pero en todo caso, deberán firmar los dos testigos y el capitán. A partir del artículo 1583 al 1592 se advierten las formalidades previstas en el Código Civil Federal; mientras que en nuestro Código Civil Veracruzano se contemplan a partir del artículo 1516 al 1525.

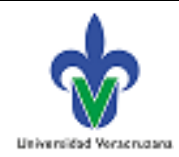

pp. $120-136$ 
ENFOQUES JURIDICOS

REVISTA MULTIDISCIPLINAR DEL CEDEGS

ISSN 26832070

Número 04

julio-diciembre 2021
Artículo: "Testamento y herencia digital”

Armando Adriano Fabre

Modesta Lorena Hernández Sánchez

DOI: https://doi.org/10.25009/ej.v0i04.2574

Testamento hecho en un país extranjero: Se otorgará por ciudadanos mexicanos que se encuentren fuera del territorio nacional ante autoridades mexicanas, como, por ejemplo: Secretarios de Legación, Cónsules, Vicecónsules, quienes podrán hacer las veces de notarios o de receptores de los testamentos, o bien ante autoridades extranjeras; en cualquier caso, se deberá cumplir lo requerido por los artículos 1593 a 1598 del Código Civil Federal. Por su parte, nuestro Código Civil Veracruzano señala disposiciones en común, a partir del artículo 1526 al 1531.

Lo hasta aquí precisado, permite advertir los diferentes contextos en los que se puede otorgar un testamento en México; sin embargo, también es preciso puntualizar cuál es el procedimiento que debe hacer el notario, posteriormente de haber dado fe de un acto jurídico de tal magnitud.

Depósito del testamento: Después de que el testador ocurre ante el notario a otorgar su testamento, éste último está obligado a dar aviso sobre la existencia de este, ante la Dirección General del Registro Público de la Propiedad y de Inspección y Archivo General de Notarías. Específicamente, en el Estado de Estado de Veracruz, los artículos 140 y 141 de la Ley del Notariado No. 585 señalan que el notario tiene el compromiso de rendir el informe correspondiente sobre los testamentos que fueron otorgados ante su fe, dentro de los diez hábiles siguientes a su realización. En el mismo contexto, conviene puntualizar que el artículo 40 transitorio de la Ley del Registro Público de la Propiedad -expedida por el entonces gobernador Fidel Herrera Beltrán-, refiere que mientras no exista el reglamento de la normativa en comento, el procedimiento de registro del testamento se deberá hacer atendiendo las disposiciones de la Ley del Registro Público de fecha 29 de diciembre de 1979 -expedida por Rafael Hernández Ochoa-. Por su parte, el artículo 36 fracción IV de la ley anteriormente citada, relacionado de manera directa y concomitante con las fracciones X y XII del numeral 2935 del Código Civil Veracruzano, disponen la obligación de inscribir el testamento ante el Registro Público de la Propiedad por ser un documento mediante el cual se adquiere, transmite, modifica, grava o extingue el dominio, la posesión u otros derechos sobre bienes inmuebles.

Conviene aclarar que en materia de derecho sucesorio se rompe el principio general del derecho, primero en tiempo, primero en derecho, en virtud de que el último testamento que haya sido otorgado por el testador será el que tenga validez; por ello, el artículo 699-A del Código de Procedimientos Civiles Veracruzano, les impone a los notarios la obligación de estar en contacto con el registrador, con la finalidad de cerciorarse si existe alguna otra disposición de fecha posterior.

Aunado a lo anterior, no puede pasar inadvertido que, durante este procedimiento de emisión y registro del testamento, el notario debe observar las disposiciones señaladas en las fracciones IV y VI del artículo 23 de la Ley del Notariado No. 585, en relación con los artículos 50 y 70 de la Ley de Protección de Datos Personales en Posesión de Sujetos

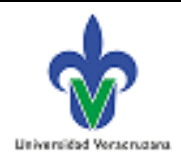

pp. $120-136$

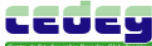


ENFOQUES JURIDICOS

REVISTA MULTIDISCIPLINAR DEL CEDEGS

ISSN 26832070

Número 04

julio-diciembre 2021
Artículo: "Testamento y herencia digital”

Armando Adriano Fabre

Modesta Lorena Hernández Sánchez

DOI: https://doi.org/10.25009/ej.v0i04.2574

Obligados, ambas legislaciones de nuestro Estado, en razón a que está obligado a resguardar toda la información que utiliza en los actos jurídicos que da fe.

\section{El testamento emergente}

La cultura que tenemos en México para otorgar un testamento es muy escasa. Lo anterior está sustentado en los datos estadísticos de los reportes del Consejo Nacional de Ciencia y Tecnología (CONACYT por sus siglas en español), en los que se advierte que hasta el momento en el que se escribe la presente colaboración, se han registrado en México 234,458 defunciones (Gobierno de México, 2021) a consecuencia del virus SARS CoV-2 y únicamente existen 4.8 millones de avisos de testamentos inscritos en el país (Gobierno de México, 2021), lo que equivale a que poco menos del $4 \%$ de la población ha otorgado una disposición testamentaria.

Actualmente, muchos mexicanos han fallecido a consecuencia del Covid-19 sin haber otorgado un testamento, por lo que la tragedia de la perdida humana, la experiencia desagradable para la familia del finado, así como la incertidumbre del destino de sus bienes y deudas, indiscutiblemente representa un conflicto que probablemente los lleve hasta puntos extremos como la desintegración familiar. No obstante, ha surgido la inquietud sobre lo que se puede hacer ante este tipo de circunstancias, donde la regla es mantener tantas actividades como sea posible de manera virtual o a la distancia, dejándonos una idea en claro, la regulación testamentaria en México debe innovarse, previniendo situaciones como la que está atravesando ahora, bajo la premisa de que el Estado debe prever e intervenir para dar fe pública en el momento que un ciudadano desee otorgar su testamento.

Bajo esa tesitura, si nos ubicamos en el supuesto de un enfermo de Covid-19 completamente aislado, se puede estimar como herramienta jurídica idónea para otorgar una disposición testamentaria, la estipulada en el Código Civil Federal como testamento privado -definido en líneas superiores-, aunque no omitimos mencionar que Códigos Civiles de diversas entidades federativas también permiten el testamento privado en ciertos casos:

El Código Civil de Veracruz en su artículo 1498, establece las condiciones en que podrá otorgarse el testamento privado siendo estas de carácter urgente:

I.-Cuando el testador es atacado de una enfermedad tan violenta y grave que no dé tiempo para que concurra notario a hacer el testamento;

II.-Cuando no haya notario en la población, o juez que actúe por receptoría;

III.-Cuando, aunque haya notario o juez en la población, sea imposible, o por lo menos muy difícil, que concurran al otorgamiento del testamento;

IV.-Cuando los militares o asimilados del ejército entren en campaña o se encuentren prisioneros de guerra.

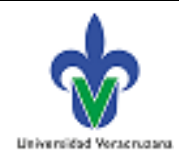

pp. $120-136$

LEVEe 
ENFOQUES JURIDICOS

REVISTA MULTIDISCIPLINAR DEL CEDEGS

ISSN 26832070

Número 04

julio-diciembre 2021
Artículo: "Testamento y herencia digital"

Armando Adriano Fabre

Modesta Lorena Hernández Sánchez

DOI: https://doi.org/10.25009/ej.v0i04.2574

El Código Civil de Nuevo León en su artículo 1462, agrega que el testamento privado está permitido en los casos siguientes:

I.- Cuando el testador es atacado de una enfermedad tan violenta y grave que no dé tiempo para que concurra notario a hacer el testamento;

II.- Cuando no haya notario en la población, o juez que actúe por receptoría;

III.- Cuando, aunque haya notario o juez en la población, sea imposible, o por lo menos muy difícil, que concurran al otorgamiento del testamento;

IV.- Cuando los militares o asimilados del ejército entren en campaña o se encuentren prisioneros de guerra.

Luego, el artículo 1639 del Código Civil de Tabasco, menciona que el testamento privado está permitido en los siguientes casos:

I.- Si el testador es atacado de una enfermedad o sufre un accidente tan violentos y graves, que no dé tiempo para que concurra al notario a hacer el testamento;

II.- Que no haya notario en la población o juez que actúe por receptoría;

III.- Que, aunque haya notario o juez en la población, sea imposible que concurran al otorgamiento del testamento; $y$

IV.- Que los militares o asimilados del ejército entren en campaña o se encuentren prisioneros de guerra.

Por último, el Código Civil de Puebla en el artículo 3308, dispone que cuando no sea posible testar ante notario, por impedimento, enfermedad, no presencia o ausencia de éste, podrá el testamento ser privado, si además el testador:

I.- Es atacado de una enfermedad o sufra un accidente, violentos y graves;

II.- Esté en una población incomunicada por razón de epidemia, aunque él no se halle atacado de ésta; o

III.- Esté en una plaza sitiada o incomunicada por cualquiera causa temporal y de fuerza mayor.

De lo anterior, se observa que únicamente el Código Civil de Puebla, señala que por motivos de una epidemia se puede otorgar un testamento sin la presencia de un notario.

Por su parte, el Código Civil Federal establece ciertas formalidades para otorgar una disposición testamentaria en circunstancias adversas: en primera, como requisito de procedencia, la persona debe estar imposibilitada para realizar un testamento ológrafo; en segunda, deberá declarar su voluntad ante la presencia de cinco testigos idóneos que escucharán al testador y/o firmarán el testamento; en tercera, éstos deberán ser oídos y, en su caso, se cotejarán las firmas ante el juez competente, para que tenga validez dicho documento, puntualizando que en el supuesto de un enfermo de Covid-19 -que debe estar totalmente aislado-, no podría cumplirse ese requisito; en el caso de que el testador no

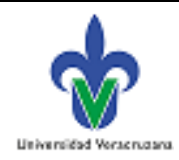

pp. $120-136$

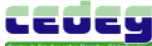


ENFOQUES JURÍDICOS

REVISTA MULTIDISCIPLINAR DEL CEDEGS

ISSN 26832070

Número 04

julio-diciembre 2021
Artículo: "Testamento y herencia digital”

Armando Adriano Fabre

Modesta Lorena Hernández Sánchez

DOI: https://doi.org/10.25009/ej.v0i04.2574

pueda escribir, uno de los testigos redactará su voluntad, pero si ninguno de éstos sabe escribir, no será necesario que se elabore por escrito, sólo bastarán tres testigos idóneos; conviene aclarar que el testamento surtirá efectos únicamente cuando el testador fallezca de la enfermedad grave que lo aquejaba, de modo que los testigos deberán dar aviso al juez competente sobre la muerte del testador y su última voluntad, siendo escuchados y declarando: el lugar, día, mes y año en que se otorgó el testamento, si reconocieron, vieron y oyeron claramente al testador, el tenor de las disposiciones del testamento, si el testador estaba en su cabal juicio y libre de cualquier coacción, el motivo por el que se otorgó y si tienen conocimiento que el testador falleció o no de la enfermedad y/o de la situación de peligro en la que se encontraba. De esta forma, si los testigos acreditan todas estas circunstancias, el juez declarará que su dicho representa el testamento formal del difunto.

Estas formalidades que estimamos complicadas de cumplir, debido a la magnitud de la enfermedad y lo que puede ocasionar el más mínimo contacto con el convaleciente de Covid-19 que desee realizar su testamento de manera privada, corroboran que durante la pandemia, la participación de la población continuará siendo casi nula.

\section{Las sucesiones en el ambiente virtual}

Hoy en día no se concibe la vida sin utilizar los entornos digitales para desarrollar cualquier tipo de actividad. Lo anterior es producto del reconocimiento del internet como derecho humano, efectuado el 16 de julio de 2012 por el Consejo de Derechos Humanos de la Organización de las Naciones Unidas (ONU por sus siglas en español), mediante la resolución A/HRC/RES/20/8 (Organización de las Naciones Unidas, 2012). Cabe decir que, con esto se buscó dotar a los ciudadanos del espacio necesario para que pudieran ejercer su derecho de libertad de expresión y acceso a la información, debido a que se trata de una prerrogativa que está sometida a la sostenibilidad y busca el progreso de las naciones.

En tal sentido, este reconocimiento internacional propició que su reconocimiento nacional se efectuará el 22 de mayo de 2013, fecha en que la Comisión Permanente del Congreso de la Unión aprobó la reforma constitucional en materia de telecomunicaciones (Gobierno de México, 2013), incorporando en el artículo 60 de la Constitución Política de los Estados Unidos Mexicanos, el derecho fundamental al acceso a las tecnologías de la información y comunicación, precisamente porque forman parte de nuestros hábitos y actividades cotidianas.

Lo anterior se considera como una situación que genera un beneficio al gobernado, ya que, a través de la red, puede ser fuente de información e intercambiar ideas. Por ello, el fomento de la alfabetización digital cada día cobra mayor fuerza y ha involucrado la protección de los datos personales de todos los usuarios, precisamente porque a través de correos electrónicos o sitios web, asiduamente registramos información tan valiosa, como por ejemplo un currículum. De igual manera, es pertinente mencionar que toda esta información personal que depositamos en la web, es parte de los derechos exclusivos al uso

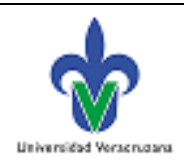

pp. $120-136$

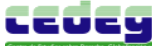


ENFOQUES JURÍDICOS

REVISTA MULTIDISCIPLINAR DEL CEDEGS

ISSN 26832070

Número 04

julio-diciembre 2021
Artículo: "Testamento y herencia digital”

Armando Adriano Fabre

Modesta Lorena Hernández Sánchez

DOI: https://doi.org/10.25009/ej.v0i04.2574

del nombre y personalidad jurídica que cada uno de nosotros tenemos, lo que lo convierte en un tema que sí requiere ser controlado, sobre todo, cuando su titular ya no se encuentre con vida.

Es por eso que como resultado de cada una de las actividades o búsquedas que realizamos constantemente en internet, ha surgido el concepto de huella digital (Madden, 2007), que en términos generales, se refiere a toda la información personal que se engloba en la web y configura la identidad digital de la persona; por ende, al existir esta forma de identificación, es menester controlar, vigilar y establecer límites al acceso de la misma, a fin de mantenerla protegida y evitar la suplantación o que se dañe la reputación de su propietario.

La existencia de la huella digital conduce a reflexionar acerca de qué es lo que va a suceder con ésta cuando una persona fallece, bajo el supuesto de que toda esa información seguirá existiendo y se convierte en una herencia digital; de ahí, la necesidad de crear la figura del testamento digital.

El notario Llopis Benlloch, afirma que cuando se habla de testamento digital, se puede referir a dos cosas: ya sea al testamento que incluye previsiones para la herencia digital de la persona como, por ejemplo: perfiles en redes sociales, archivos de audio, video, entre otros, o bien, el testamento que se hace online por internet; aclarando que lo primero sí existe, mientras que lo segundo no. De este modo, la denominación de testamento digital puede admitirse para una previsión mortis causa que afecte exclusivamente a bienes o derechos digitales (Llopis Benlloch, 2016).

Este concepto se encuentra dividido entre los autores, para Judith Giner, es un documento que permite que la persona deje instrucciones sobre qué hacer con su presencia digital una vez que fallezca; en dicho documento debe incluirse la relación de todas sus posesiones digitales, es decir, claves de acceso, así como una autorización para que alguien de confianza pueda acceder a todo ese contenido cuando fallezca el titular, mismo que podrá dividirse en grupos que pueden gestionarse por separado, tales como: cuentas de correo electrónico, cuentas de servicios y contraseñas, servicios de suscripción, cuentas bancarias y otros fondos financieros, contenido personal en internet, contenido personal físico como ordenadores, discos duros, memorias USB y móviles (Giner Candía, 2016).

Por otra parte, Carlos Luch, sostiene que el término de testamento digital no existe, en razón a que no hay nada que distinga la herencia digital de la herencia analógica, esto porque el formato digital de determinados archivos, o su ubicación, no los distingue de las cosas en físico y no les otorga ningún trato diferenciado en orden a su destino o sucesión (Luch Cerdá, 2016).

Lo cierto es que la revolución digital existe y ha dado a conocer las nuevas necesidades de la sociedad; tratar de escapar de los efectos que trae el uso del mundo digital es incongruente e irracional. Por ello, es que se estima conveniente fijar un concepto de testamento digital como una expresión de voluntad que defina el destino de los bienes

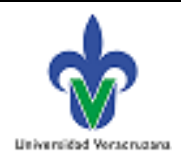

pp. $120-136$

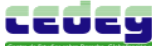


ENFOQUES JURIDICOS

REVISTA MULTIDISCIPLINAR DEL CEDEGS

ISSN 26832070

Número 04

julio-diciembre 2021
Artículo: "Testamento y herencia digital”

Armando Adriano Fabre

Modesta Lorena Hernández Sánchez

DOI: https://doi.org/10.25009/ej.v0i04.2574

digitales y la identidad digital, una vez que el testador fallezca. Esto sigue siendo motivo de debate entre los juristas; no obstante, es importante tomar en consideración la cantidad de datos que cotidianamente registramos en la web, derivados de cuentas de correo de correo electrónico, blogs, canales audiovisuales o chats; lo que lo convierte en un tema que debe ser regulado.

\section{Regulación del testamento digital}

Actualmente, países europeos como Francia y España, han buscado mantenerse a la vanguardia en temas jurídicos, fijándose como pioneros en el tratamiento de las sucesiones y su relación con las tecnologías de la información y comunicación. En el caso de Francia, con la Ley número 2016-1321 por una república digital, expedida el siete de octubre de 2016, se posicionaron como único precedente sobre la regulación de la huella digital después de la muerte del usuario, abordando el tema de la herencia digital y el derecho a la muerte digital, con el propósito de que las personas dispongan instrucciones para el almacenaje, borrado o la comunicación de su muerte, mismas que pueden ser generales o específicas, así como la designación de la persona responsable de ejecutar las voluntades digitales, a su vez, también se establece la manera en la que se procederá en caso de no existir instrucciones precisas y cuestiones de propiedad intelectual.

Por su parte, Cataluña tomó como referencia a Francia y en el año 2016 aprobó la Ley de voluntades digitales para el caso de muerte, la cual modifica las disposiciones del Código Civil y trata de ordenar la presencia de las personas en los entornos digitales durante su minoría de edad, así como los supuestos de capacidad judicialmente modificada para después de su muerte, en este último, la ley dispone que con la manifestación de las voluntades digitales, la persona ordena a su heredero, legatario, albacea, administrador o persona de confianza designada para ello, que después de su muerte, ejecute determinadas acciones ante los prestadores de servicios digitales, mismas que pueden consistir, ya sea en la cancelación de cuentas activas, extinguiendo de esa forma su huella digital, o bien, comunicar su muerte por dichos medios. La ley catalana prevé la posibilidad de que las voluntades digitales se ordenen por medio de un documento de voluntades digitales que debe inscribirse en el registro electrónico de voluntades digitales.

En diciembre del año 2018, se publicó en España la Ley Orgánica de protección de datos personales y garantía de los derechos digitales, que en su artículo 96 establece el derecho al testamento digital, señalando que los familiares o herederos del fallecido podrán dirigirse a los prestadores de servicios de la sociedad de la información al objeto de acceder a dichos contenidos e impartirles las instrucciones que estimen oportunas sobre su utilización, destino o supresión, con la excepción de que el fallecido hubiere expresado lo contrario, o así lo establezca una ley.

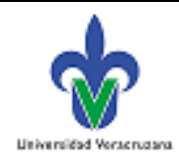

pp. $120-136$ 
ENFOQUES JURIDICOS

REVISTA MULTIDISCIPLINAR DEL CEDEGS

ISSN 26832070

Número 04

julio-diciembre 2021
Artículo: "Testamento y herencia digital”

Armando Adriano Fabre

Modesta Lorena Hernández Sánchez

DOI: https://doi.org/10.25009/ej.v0i04.2574

\section{Conclusiones}

La pandemia por SARS Cov2, causante de la enfermedad Covid- 19, hizo su aparición en México y nos obligó a enfrentarnos a escenarios insólitos que jamás consideramos que pasarían, quedando de manifiesto la desactualización de nuestras leyes en materia de bienes y sucesiones. Esto ha hecho evidente la necesidad de innovar y mantenernos a la vanguardia en los temas relacionados a las nuevas tecnologías de la información y comunicación, puesto que, en mayor medida utilizamos entornos digitales para desarrollar nuestras actividades.

En ese sentido, es vital que nuestros Códigos Civiles -Federal y Estatal- contemplen las directrices que se deben seguir para que el ciudadano decida que tratamiento se le dará a toda esa información personal que circula en las plataformas digitales -facebook, twitter, instagram, blog personal, red de mensajería, entre otros- después de su muerte, por ser parte de su patrimonio, porque contiene datos que pertenecen a su identidad.

La huella y la herencia digital son figuras que nacieron a consecuencia del uso de dichas plataformas, de modo que, esto hace necesario su regulación para que el ciudadano cuente con la normativa que acepte el desarrollo tecnológico y la creación de nuevos instrumentos que garanticen a plenitud su última voluntad, como lo está efectuando Francia y España. 
ENFOQUES JURIDICOS

REVISTA MULTIDISCIPINAR DEL CEDEGS

ISSN 26832070

Número 04

julio-diciembre 2021
Artículo: "Testamento y herencia digital"

Armando Adriano Fabre

Modesta Lorena Hernández Sánchez

DOI: https://doi.org/10.25009/ej.v0i04.2574

\section{Fuentes de consulta}

Asprón Pelayo, J. M. (2008). Sucesiones. México: Mc Graw Hill.

Barea, J. (1998). Teoría General del Testamento. Barcelona: Fundación Enciclopedia catalana.

Bonnecase, J. (1993). Tratado elemental de derecho civil. México: Harla S.A. de C.V.

Burgi, B. (2006). Instituciones de Derecho Civil. México: TSJDF e INCANM A.C.

De Pina Vara, R. (2019). Derecho civil mexicano (20 edición, primera reimpresión ed., Vol. II). México: Porrúa.

Flores Márquez, V. (1989). El testamento como institución jurídica. Revista digital de derecho (1). Recuperado el 21 de marzo de 2021, de https://revistascolaboracion.juridicas.unam.mx/index.php/podium-

notarial/article/view/16089/14410

Giner Candía, J. (2016). El testamento digital sí existe y ya ha llegado. En R. Olivia León, \& S. Valero Barceló, Testamento ¿Digital? España: Desafíos legales \#RetoJCF Juristas con futuro.

Gobierno de México. (22 de mayo de 2013). En México, el acceso a internet es un derecho constitucional. México. Recuperado el 08 de Julio de 2021, de https://www.gob.mx/gobmx/articulos/en-mexico-el-acceso-a-internet-es-underecho-constitucional

Gobierno de México. (01 de mayo de 2021). Datos sobre el coronavirus. Obtenido de https://datos.covid-19.conacyt.mx/

Gobierno de México. (08 de julio de 2021). Datos sobre el coronavirus. Obtenido de https://datos.covid-19.conacyt.mx/

Gobierno de México. (08 de julio de 2021). Registro Nacional de Avisos de Testamento. Obtenido de http://www.testamentos.gob.mx/pestadistica.php?ref=2

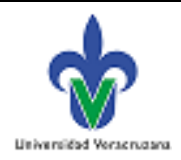

pp. $120-136$ 
ENFOQUES JURIDICOS

REVISTA MULTIDISCIPLINAR DEL CEDEGS

ISSN 26832070

Número 04

julio-diciembre 2021
Artículo: "Testamento y herencia digital"

Armando Adriano Fabre

Modesta Lorena Hernández Sánchez

DOI: https://doi.org/10.25009/ej.v0i04.2574

Gobierno de México. (01 de mayo de 2021). Registro Nacional de Avisos de Testamento. Obtenido de http://www.testamentos.gob.mx/pestadistica.php?ref=2

Gutiérrez Pérez, R. (1996). La necesidad de dar una nueva regulación en el Código Civil para el Distrito Federal. México: Escuela Libre de Derecho.

Llopis Benlloch, J. (2016). Con la muerte digital no se juega: el testamento online no existe. Testamento ¿Digital? En R. Olivia León, \& S. Valero Barceló, Testamento ¿Digital? España: Desafíos legales \#RetoJCF Juristas con futuro.

Luch Cerdá, C. (2016). El reto de una muerte digital...Digna. En R. Olivia León, \& S. Valero Barceló, Testamento ¿Digital? España: Desafíos legales \#RetoJCF Juristas con futuro.

Madden, M. (2007). Digital footprints: online identy management and search in the age of transparency. Whashington DC: Pew internet \& american lofe project. Recuperado el 12 de abril de 2021, de https://www.academia.edu/412941/Digital_footprints_Online_identity_managem ent_and_search_in_the_age_of_

Magallón Ibarra, J. (1997). Instituciones de Derecho Civil. México: Porrúa.

Organización de las Naciones Unidas. (2012). Resolución aprobada por el Consejo de Derechos Humanos A/HRC/RES/20/8. Nueva York: Organización de las Naciones Unidas. Recuperado el 18 de marzo de 2021, de https://undocs.org/pdf?symbol=es/a/hrc/res/20/8

Pérez Contreras, M. (2010). Derecho de familia y sucesiones. México: Colección Cultura Jurídica. Recuperado el 21 de marzo de 2021, de http://ru.juridicas.unam.mx:80/xmlui/handle/123456789/12174

Ríos Hellig, J. (2012). La práctica del derecho notarial (Octava edición ed.). México: Mc Graw Hill.

Rojina Villegas, R. (1990). Compendio de derecho civil, bienes, derechos reales y sucesiones. México: Porrúa.

Testamento público simplificado. El juicio sucesorio se puede tramitar judicialmente o ante notario, a elección de los herederos, 2017474 (Cuarto Tribunal Colegiado en Materia

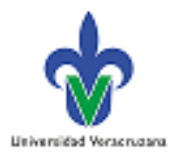

pp. $120-136$ 
ENFOQUES JURIDICOS

REVISTA MULTIDISCIPLINAR DEL CEDEGS

ISSN 26832070

Número 04

julio-diciembre 2021
Artículo: "Testamento y herencia digital”

Armando Adriano Fabre

Modesta Lorena Hernández Sánchez

DOI: https://doi.org/10.25009/ej.v0i04.2574

Civil del Primer Circuito 13 de Julio de 2018). Recuperado el 21 de marzo de 2021, de https://sjf2.scjn.gob.mx/detalle/tesis/2017474

Testamentos ológrafos. Son susceptibles de interpretación, 164661 (Tercer Tribunal Colegiado en Materia Civil del Primer Circuito 28 de enero de 2010). Recuperado el 29 de marzo de 2021, de https://sjf2.scjn.gob.mx/detalle/tesis/164661 